\title{
The correspondence of Giovanni Santini and Giuseppe Lorenzoni, directors of the Astronomical Observatory of Padua in the 19th century
}

\author{
Luisa Pigatto \\ INAF - Osservatorio Astronomico di Padova, Italy
}

\begin{abstract}
Giovanni Santini was appointed director of the Astronomical Observatory of Padova from 1817 to 1877. His scientific correspondence covers a period from 1807 to 1874. Most of the letters are from Italian and European astronomers, mainly concerning astronomical subjects. In actual fact, all Santini's activity was devoted to the classical astronomy, mainly to the new comets and planets orbit calculation, as far as to the compilation of a catalogue of almost ten thousand stars. From 1821 to 1828, he was involved in geodetic observations in order to determine the difference of longitude between Milan-Padua and Padua-Fiume. Giuseppe Lorenzoni was appointed director after Santini's death, from 1877 to 1913. Since 1873, he took part in the Italian Geodetic Commission to which he devoted almost all his scientific activity. Lorenzoni's scientific correspondence was partly lost for war reasons. A partial correspondence with Giovanni Virginio Schiaparelli and almost the complete correspondence with Pietro Tacchini, were recovered after the second World War. Santini and Lorenzoni correspondence cover a period about a hundred years long. So, it is an important tool of knowledge for the history of Padova Astronomical Observatory in the 19th century, for its scientific activity, and for the relationship among Italian and European astronomers and institutions.
\end{abstract}

Key words Santini - Lorenzoni - Astronomical Observatory of Padua, geodesy - meteorology

\section{Introduction}

«Of Astronomy not only fruit, but ramifications are Geography, Chronology, Navigation, without which the commerce cannot not only be practised, not even the social life can be conceived. Not to mention agriculture - nurse of mankind - which is in great part governed by the demonstrated order of the celestial motions and seasons [...]. Other part exists

Mailing address: Dr. Luisa Pigatto, INAF - Osservatorio Astronomico di Padova, Vicolo Dell'Osservatorio 5, 35122 Padova, Italy: e-mail: luisa.pigatto@oapd.inaf.it also and derivation of astronomy of which all the people need which, if removed, a great disorder would arise. This is the consistent subdivision of the diurnal and nocturnal time in sure hours, which have the task of regulating all the services and trades» (Toaldo, 1766).

With these words, Giuseppe Toaldo (17191797), professor of astronomy, geography and meteorology at Padua University and director of the astronomical Observatory of Padova from 1767 to 1797 (Pigatto, 2000), introduced the beginning of the lessons for the academic year 1766-67, in order to defend astronomy from the easy accusation of being useless science. In this way he stated that task of the astronomer was that of taking care of all the disciplines mentioned here, in addition to that of making regular meteorological observations. 
A hundred and thirteen years later, Giovanni Virginio Schiaparelli (1835-1910), director of the Milan-Brera Observatory, published a letter in the newspaper Il Secolo, February $18 / 19,1879$, answering the many criticisms the Observatory had received on the occasion of earthquakes. He wrote:

«Brera Observatory is an astronomical observatory, and does not have any obligation to take care itself of earthquakes, which are geological phenomena». He concluded: «In science as well in industry it becomes more and more urgent every day to divide up the work. The astronomer who wants to make the meteorologist and the geologist at the same time, runs the risk of making everything badly. We, I repeat, we are astronomers, and not geologists: we are meteorologists under the circumstances and for supplying the lack of suitable institutions in this town».

These two quotations open and close a period during which a deep transformation had been happening in science: new disciplines such as Physics, Chemistry, Geology were improving or born in the 18th century. In the 19th century they were perfecting more and more, and specialisation was needed to practise them. Astronomers continued to practise Geodesy for all the 19th century and the beginning of the 20th century, mainly because the method of geodetic triangulation on the ground is based on the observation of stars of which the coordinates are known in a very precise way, and many European observatories produced star catalogues. At the same time, meteorological observations continued to be made in the Italian observatories following the tradition which was born in the 18th century.

\section{Santini's correspondence}

Giovanni Santini (1787-1877) (fig. 1) was appointed astronomer assistant at the Observatory of Padua in 1806, during the Italic Reign established by Napoleon in 1805 . He was appointed director of the Observatory of Padua in 1817 and hold this position till his death in July 1877 (Pigatto, 1996).

Santini had a great deal of correspondence: more than a thousand letters are preserved at the Padua Observatory historical archive. He corre-

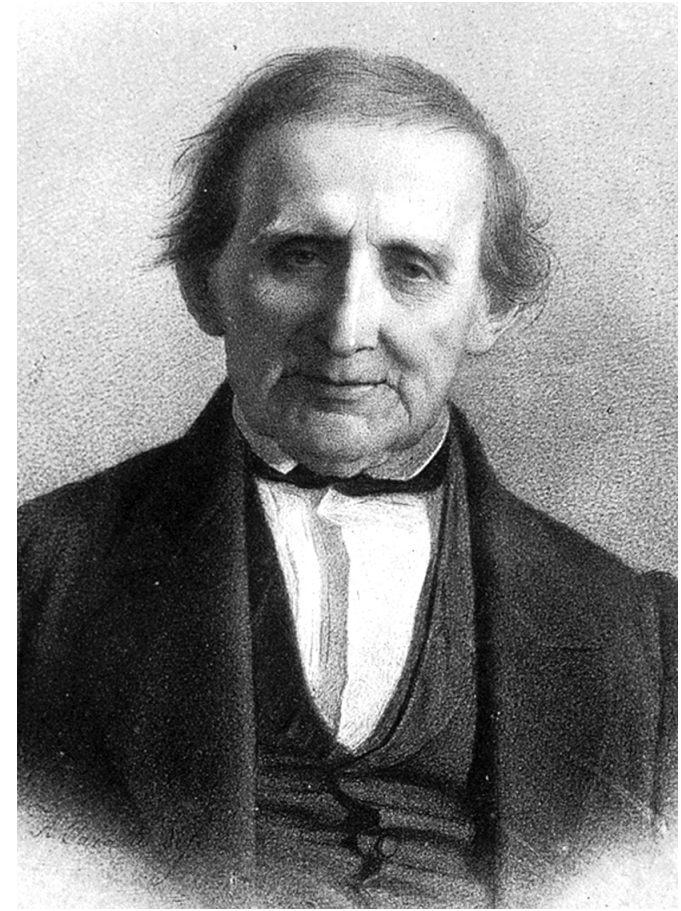

Fig. 1. Portrait of Giovanni Santini (1787-1877).

sponded with many Italian and European astronomers, among them Barnaba Oriani, Francesco Carlini (125 letters), Giuseppe Bianchi (50 letters), Giambattista Amici (29 letters), Giovanni Virginio Schiaparelli, François Xavier von Zach (38 letters), Friedrich W. Argelander, George B. Airy, Wilhelm von Biela, John Herschel, Joseph and Karl von Littrow (49 and 84 letters respectively), Heinrich Schumacher (27 letters), Otto and Wilhelm Struve and many others. He knew personally many of these astronomers who visited him in Padova, such as the baron von Zach, John Herschel, Joseph and Karl von Littrow, Otto and Wilhelm Struve, or he met during his journey through Germany that he made in autumn 1843 with Roberto De Visiani (1800-1878) professor of botany and director of the Botanical Garden at the University of Padua (their itinerary was Trieste, Vienna, Dresden, Leipzig, Berlin, Hamburg, Altona, Regensburg, Munich, Trento). 
In Santini's scientific correspondence, we can't fail to notice the very scarce interest in meteorological subjects even if meteorological observations started regularly at the Observatory with Giuseppe Toaldo, and continued till the 20th century. As a matter of fact, Santini devoted all his energy to positional astronomy, especially to calculate orbits of new comets and planets, to make a ten thousand stars catalogue and update astronomical instruments (Pigatto, 1988). He was advised by his first teacher in astronomy Barnaba Oriani (1752-1832), director of Brera-Milan Observatory, who wrote to him:

«Don't get tired to make and remake all the possible observations, and devote yourself to the bad weather theory when you can't see the sky» (Oriani, 1806).

Almost at the same time, his colleague and friend Francesco Carlini (1783-1862), astronomer at the Brera Observatory, wrote to him:

«A good sextant being lacking to observe the correspondent altitudes, you could measure your quadrant deviation by means of the right ascensions of the 36 stars determined by Maskelyne, so you should be able to make important observations and the astronomy in Padua, because of you, could elevate far beyond the atmosphere» (Carlini, 1807).

\section{Santini's geodetic observations}

Since February 1821, Francesco Carlini started to write to Santini about the project of determining the difference of longitude between Milan and Padua, by observing instantaneous fires on the top of Mount Cimone, which was also visible from Florence. As a matter of fact, Milan-Brera Observatory was involved in the great geodetic campaign, supported by French, Piedmontese and Austrian governments, in order to complete the measurement of the 45th parallel from Atlantic to Adriatic sea. Santini agreed to his friend's proposal, as it comes out in Carlini's letters to him from 1822 to 1823 . However, Santini couldn't avoid them because they were commanded by Austrian Government under which all the Venetian territory was submitted since November 1813.
On July 14, 1824 he received an official letter from the lieutenant-colonel Antonio Campana (1772-1841), director of the «Istituto Geografico Militare» in Milan (Lombardia and Veneto regions formed the «Regno LombardoVeneto»), who informed him that:

«Mr. La Place, the President of the Bureau of Longitudes, wishes that the difference of longitude between Milan and Fiume [modern Rijeka] should be measured in this year by the Austrian General Staff by means of instantaneous fire signals, as a continuation of the measurement made by the French from Milan as far as the Cordouan tower near Bordeaux» (Campana, 1824).

Campana was ordered from the lieutenantmarshal Chief of Staff, baron von Wimpffen, to inform Santini about the geodetic observations. On 13 August Nicolò Da Rio, director of the philosophical-mathematical Faculty of the University of Padua, communicated to Santini with an urgent letter that he had to get ready to make observations of the instantaneous fires on Mount Baldo in compliance with a dispatch of the «Sovereign Imperial Government» to the Faculty arrived 11th August. The Milan and Padua Observatories constituted the trigonometric base, and the astronomers Carlini and Santini were responsible for the observations. In his letter, Campana included a «Project of instructions for the instantaneous fires to be made during the month of August of this year in order to determine the difference of longitude between Milan and Padua». They are very clear and detailed instructions in 16 points concerning the days for the signals to be observed at the top of Mount Baldo, the weight of charge of powder, the procedure to be followed in giving the signals and recording the time etc. (see Appendix).

On May 29, 1825, Campana sent to Santini a copy of «Instructions concerning the instantaneous fires to be made on June 25 and next evenings of the current year in order to determine the difference of longitudes between Milan, Padua and Fiume», signed by the colonel Fallon from Vienna, May 17, 1825 (Campana, 1825). The fires had to be repeated at the top of Mount Baldo, and new ones had to be organised at the top of Mount Maggiore in Istria [modern Croatia]. In this second campaign, the fires on 
Mount Baldo had to be observed from Brera Observatory in Milan and from Padua Observatory, those of Mount Maggiore from St Mark's tower in Venice and from an equipped station in Fiume. For the intermediate station in Venice the General Staff sent from Vienna: a Festbauer half second pendulum clock, an Arnold chronometer, a Fraunhofer 60in $(163 \mathrm{~cm})$ focus and 48 lines $(11 \mathrm{~cm})$ aperture reflecting telescope, a Fraunhofer $3 \mathrm{ft}(97 \mathrm{~cm})$ focus achromatic refracting telescope. For Fiume station Vienna sent: a Molineux astronomical pendulum clock, a Dollond transit instrument with a 30 in $(82 \mathrm{~cm})$ focus and 2 in $(5 \mathrm{~cm})$ aperture refracting telescope, a Liebher astronomical repeating theodolite from Munich, a $12 \mathrm{in}(33 \mathrm{~cm})$ diameter repeating theodolite of Vienna Polytechnic Institute, a Festbauer half second pendulum clock. The transit instrument had to be placed in the Scarpa Garden in Venice, «in the same place where the French astronomer Biot [Jean-Baptiste Biot (1774-1862)] had placed his own instrument». The colonel Giacomo Marieni, cartographer, was entrusted with the task of observing with the transit instrument, and informing Santini about the results of the Mount Maggiore observations (10 letters of Marieni to Santini from August 16, 1827 to September 1, 1827).

Santini carried out his task, and on April 1828 he received a letter from Milan signed by the major Martini (for Campana) who informed him that «His Excellency lieutenant-marshal Chief of Staff, baron von Wimpffen, with his venerated ordinance», had prescribed that a copy of the report concerning «the works of Geodesy and Astronomy performed in Piedmont and Savoy in order to measure the arc of the medium parallel» had to be sent to him as «a gratitude certificate for the useful part you have given to the execution of this scientific work» (Martini, 1828). The geodetic and topographic campaigns performed at that time by the General Staff of Austrian government, gave as a result the «Map of the Lombardo-Veneto Reign», engraved in 1833.

In 1859, the Lombardia region was annexed to the Piedmont Reign and in 1861 the new Kingdom of Italy was born. The Veneto region was annexed to the Kingdom of Italy in 1866, while the Pontifical State was annexed in 1870. Schiaparelli, astronomer at Brera Observatory from 1860 and then director of the observatory after Carlini's death in 1872 was appointed member of the «Permanent Commission to measure the European degree» in 1864 (Tucci and Valota, 1983). In a letter of 10 July 1865, Schiaparelli updated Santini about the measure of the European degree which had just started from Sicily under the Italian General Staff direction. «All the triangles performed by the French along the mean parallel (the 45th one) will be revised, and a double chain of triangles will be performed along the [Italian] peninsula, so that all the meridian and parallel lines to be connected, will be calculated». Schiaparelli continued informing Santini that he had to go to Berlin to take «the normal 'tesa' [the old French unit of length, the 'toise', corresponding to 1.944 metres] so that it can be compared to those of Bessel, Struve and Schumacher. Such a comparison will be performed by a Commission formed by Hansen, Baeyer, Repsold and Dove, who will take advantage of this occasion to make a comparison among all the units of length used for the geodetic bases in different countries». It is worth putting into evidence that for this geodetic campaign the unit of length was again the old French 'toise' used since the campaigns performed in the 18th century. The Commission to measure the European degree constituted the first official collaboration among the European countries. Schiaparelli was not very enthusiastic at being entrusted with the task of geodetic observations. In the same letter he wrote:

«I'm frightened of considering the very large burden we are going to shoulder little by little; then I must admit that, among all the astronomical works, these ones are those I don't like most. Above all, I'm worrying about the idea of performing the difference of longitudes by means of the electric telegraphy, about which I'm quite ignorant» (Schiaparelli, 1865).

Leaving out Schiaparelli's worries, a new era was born in the geodetic measurements: the telegraphic signals substituted definitively the powder instantaneous fire signals.

In 1869 the 82 years old Santini was appointed member of the «Permanent Commission to measure the European degree» by the 
Italian government. In 1873, he was invited to Rome because of the constitution of the «Italian Permanent Commission». Santini delegated his young assistant astronomer Lorenzoni to represent him.

\section{Lorenzoni's correspondence}

Giuseppe Lorenzoni (1843-1914) (fig. 2) was appointed director of Padua Observatory after Santini's death in 1877 (Pigatto, 1996), actually he had replaced the more than eightyyearold Santini in all the tasks of direction for years. Great part of his correspondence both with Italian and foreign astronomers was lost during the World War II. A premise is needed to throw partial light on the destiny of Lorenzoni's correspondence. His preparation at Santini's school was first class, as far as theoretical astronomy, geodesy, and optical instrumentation are concerned. Lorenzoni was of high intelligence, of mild and kindness nature, well disposed towards the students who attended his lessons at the Observatory, where these ones and the colleagues gathered whenever an extraordinary astronomical event such as the apparition of a new comet or an eclipse took place. This fact can be an explanation why Gregorio RicciCurbastro (1853-1925) [better known as Ricci], the famous mathematician professor at Padova University (Zaupa, 1996), kept the letters that Lorenzoni had received from many astronomers, perhaps in order to write a biography of his esteemed and beloved colleague. At the end of the second World-War Giorgio RicciCurbastro, Gregorio's son, who lived in Faenza, sent two packets of these letters to Giovanni Silva (1882-1957), 6th director of Padua Astronomical Observatory. The reason why this correspondence was in the hands of Ricci's heirs should be attributed to the unexpected death of Gregorio in 1925. The family lived in Padova, but after Ricci's death, it moved to Romagna where they had some property.

The first packet contained 24 letters written by Schiaparelli to Lorenzoni and 26 Lorenzoni's rough copies of answers to Schiaparelli, in the period from 1879 to 1891 . Most of the letters are of astronomical subject, in particular they con-

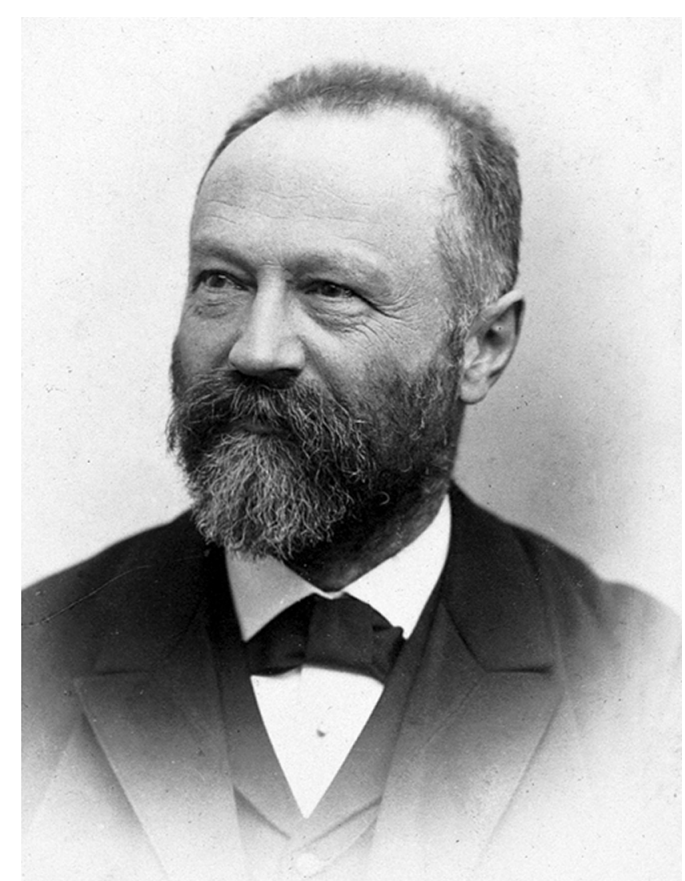

Fig. 2. Portrait of Giuseppe Lorenzoni (1843-1915).

cerns astronomical as well as geodetical instruments. As mentioned above, Schiaparelli was a member of the Italian Geodetic Commission from 1864. In 1873 Santini was appointed honorary member because of his age, at the same time Lorenzoni became regular member. We can argue that many letters are missing, for example those concerning the project of Lorenzoni, accepted by the Commission, of determining the difference of longitude between Milan, Padua, Vienna and Munich by the telegraphic method following the proposal suggested by Theodor von Oppolzer (1841-1886), professor of astronomy and geodesy at Vienna University. These determinations were performed in 1875 by Lorenzoni in Padua, and Giovanni Celoria (1842-1920), astronomer of Brera Observatory, in Milan, and the results (Celoria and Lorenzoni, 1879) were published as «Publication of the degree Commission» by Brera Observatory (Schiaparelli, 1879). Figure 3 shows a picture of the Commission members in 1880. 


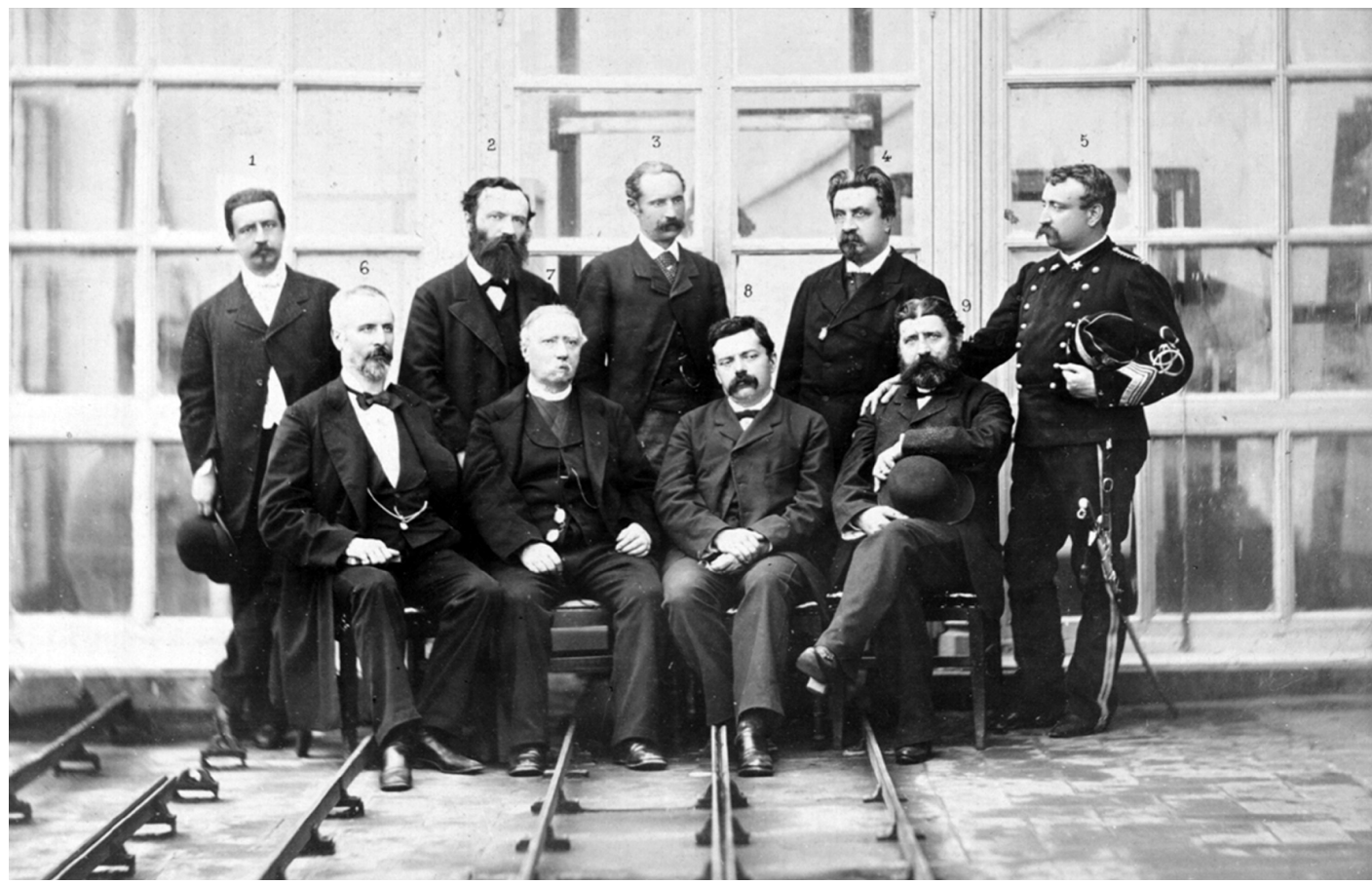

Fig. 3. Italian Commission to measure the European degree. 15 June 1880. Standing (left to right): Nobile, Lorenzoni, Obelholtzer, General Mayo, the President, Colonel Ferrero. Seated (left to right): Betocchi, General Ricci, Schiaparelli, Respighi (photograph, Astronomical Observatory of Padua, historical archives).

\section{Lorenzoni-Tacchini correspondence}

In the second thick packet sent by Giorgio Ricci-Curbastro to Silva, 290 original letters written by Pietro Tacchini (1838-1905) to Lorenzoni and 177 rough copies of letters by Lorenzoni to Tacchini were preserved. They cover the period from 1870 to 1905 , the year of Tacchini's death. Part of the original letters by Lorenzoni is preserved at Rome Observatory, at Monte Porzio, part at the «Ufficio Centrale di Ecologia Agraria» in Rome. Tacchini studied astronomy at Padua Observatory under Giovanni Santini. In 1863 he was appointed adjunct astronomer to Palermo Observatory, where he began research on solar physics. In 1879 he succeeded the Jesuit Angelo Secchi (1818-1878) as director of the Observatory at the Collegio Ro- mano and became director of the Central Meteorological Office. The Meteorological Office was founded by a Royal Decree, issued on April 9, 1865, in order to re-organise the meteorological service of the Italian Kingdom. In 1875 a revision was performed by a Commission of which Tacchini took part from 1877 (Granata, 2000).

When Lorenzoni was appointed astronomer assistant in 1863, he was entrusted with the task of reorganising and updating the meteorological observations and instruments of Padova Observatory. At the beginning, he followed Secchi's method illustrated in the «Bulletin» published by the Jesuit, then he adopted the rules of the new national Meteorological Office of which Tacchini was appointed director in 1879 . The friendship between the two Italian as- 
tronomer began during the Italian party to Sicily to observe the total solar eclipse of 22 December 1870 (Pigatto, 1998). Since then, they exchanged letters about all their scientific activity, i.e. astronomy, astrophysics, meteorology and geodesy; they helped each other in many events concerning scientific collaboration, their pupils position, improvement and purchase of instruments. As an example, we mention here the preparation of the Italian party to India to observe the 1874 transit of Venus (Pigatto and Zanini, 2001), the purchase of $187 \mathrm{~mm}$ aperture and $3 \mathrm{~m}$ focal length Merz Refractor (Pigatto and Zanini, 2002). This instrument had been purchased in 1881 (Lorenzoni, 1881a) from the heirs of Baron Ercole Dembowski (1812-1881), astronomer of Milan and famous observer of double stars. On 27 January 1881 Schiaparelli, after Dembowski's death, had immediately informed Lorenzoni that his heirs had put on sale the refractor (Schiaparelli, 1881a) and successively he was intermediary for purchasing the telescope as well as the small dome of Dembowski's observatory (Schiaparelli, 1881b). However, thanks to Tacchini and his influence on the Minister of the Public Education, Lorenzoni obtained the indispensable funds to buy telescope and dome, and to built the pavilion to shelter the instrument (Lorenzoni, 1881b; Tacchini, 1881). In all the correspondence, Tacchini demonstrates a great confidence on Lorenzoni's competence and judgement about every kind of instrument, astronomical as well as meteorological. Tacchini asked often his friend for some of his instrument improvement at Padua observatory workshop. Lorenzoni always agreed Tacchini's request with generosity: this explains their long and sincere friendship till Tacchini's death.

As far as the meteorology is concerned, Lorenzoni had improved the meteorological equipment since 1864. In 1865 a new iron balcony where to place the meteorological instruments in a niche was built at north of the Observatory tower, in 1869 he got the Parnisetti-Brusotti anemograph, in 1871 the balcony was substituted with a masonry terrace, in 1874 the iron niche was substituted with an wooden one, in 1877 he got a pluviometer, in 1880 maximum and minimum thermometers, in 1886 an helio- phanograph (Antoniazzi, 1915). Lorenzoni congratulated Tacchini on his appointment to the meteorological Commission, because he knew that his friend might be able to renew the Italian meteorological network (Lorenzoni, 1877). Tacchini's pragmatism came out immediately. On 17 August 1879 he wrote to Lorenzoni about the opportunity of founding new meteorological stations in the province, in order to record daily data on rain and temperature (Tacchini, 1879). On January 1880 Lorenzoni wrote a Memorandum after Tacchini's visit to Padua:

«On 4 January 1880, Prof. Tacchini director of the Central Office of Meteorology, came to visit the Observatory. [...] He promised us 120 liras per year for the barograph and thermograph data reduction. He also promised to send us a barometer, two thermographs and two thermometers with a scale down to minus 20 . He invited us to present the expense project to study the Padova climate within January. Invited us to found several pluviometric stations in the province, and promised that he would send instructions, forms, pluviometers etc. He said that he was planning to found the 69 provinces' chief towns observatories in small towns, from which all the pluviometric observatories of the province had to depend» (Lorenzoni, 1880).

In 1888 Tacchini sent Lorenzoni a seismoscope (Lorenzoni, 1888), so earthquake records started to be made together with meteorological observations. As a matter of fact, Tacchini had promoted seismological observations in the meteorological observatories, and the «Central Meteorological Office» became «Central Office of Meteorology and Geodynamics at the Roman College», as the heading of Tacchini's letters shows. Once again Lorenzoni gave great care to the new task and instruments. On April 22, 1890 he wrote to Tacchini:

«The small bar seismoscope doesn't work again, even if we took care of adjusting it at the maximum sensibility, so that some time the small bar falls down because of the small shakes coming from the clock's irregular wheel mechanism. So, we could say that an earthquake has just happened, if the other near seismoscope didn't move at all. We have to say (like you also had once supposed), that certain kind of shakes are not perceived by the instrument; by chance, during the last earthquake of which we informed this Office, the assistant and me were both in the meridi- 
an room, and because of the shake all the pendulous objects inside the room started to swing, included the tube coming from the roof which supports the two gas lamps, while the small bars stayed motionless» (Lorenzoni, 1890).

Even the following letter, concerning seismological instruments, deserves some attention:

«Today I have been able to visit Mr. Organo and his apparatuses. He is an well-off maker of ink and sealing-wax, and trades in stationery. He told me of being in very excellent relationship with Goiran and Belletti [instrument makers] and of being interested in seismological studies for hobby. As a matter of fact, he keeps several instruments at home, well enough installed, which are arranged for signalling undulatory as well as jolting earthquakes. The signal is given by electric bells, on which the current is closed by the swing or helicoidal motions generated by the earthquake. The same current starts to move the clock which is stopped at twelve all the time. Organo has also mounted a tromometer at his own expenses, and he observes it very often also all night. On my opinion, he deserves the Bulletin he wishes to receive, even because sometimes he could give some important information» (Lorenzoni, 1893).

The correspondence in the nineties mainly concerns meteorological instruments - especially anemometers - and observations. Letters are decreasing in number, especially after 1893. The last letter is a greetings card Tacchini wrote to Lorenzoni for his name-day - Saint Joseph on 17 March 1905, seven days before his death.

\section{Appendix}

Project of instructions for the instantaneous fires to be made during the month of August of this year in order to determine the difference of longitude between Milan and Padua

1. The highest top of the Mount Baldo is visible both from Milan and Padua. For this reason, the instantaneous fires have to be made at a little distance from the trigonometric signal built on this mount.

2. The days for the signals are fixed on August 22, 23, 24 till 27 of this year. In this way, the medium day falls on the new moon epoch.

3. Every signalling consists of 10 instantaneous fires, which are lighted one after the other in the exact interval of every 4 minutes (mean solar time).

4. Taking in mind the considerable distance of about 18 German miles between Milan and Mount Baldo, a 3/4 of Vienna pound charge of medium quality powder for instantaneous fires will be used. In the foggy evenings, when at nightfall vapours are accumulating on the Lombardia and Veneto planes, the charge can be increased till 1 pound. An artilleryman will be given to the signalmen to manipulate the powder.

5. Every day of signalling, the first instantaneous fire will be made at 9 p.m. (mean solar time at Mount Baldo). 6. Since the signalman hardly can trust the chronometer's running during 6 days, and since it can happens that the clock stops, so, in order to prevent such an unfortunate accident, the signalman will receive the useful signal from the Geographer Engineer placed near Mount Baldo who knows the true time.

7. The notifying signals consist of 3 bursts of powder following one another every two minutes. The signaller observes them by the chronometer and lights his first signal after 30 minutes; however, the Geographer Engineer will give his first signal at 8 and 26 p.m. (mean solar time of Mount Baldo).

8. The instantaneous fires will be observed from the Brera Observatory in Milan by the astronomer Carlini, and from the Observatory of the University in Padua by the astronomer Santini.

9. Although the instantaneous fires will be made following the mean solar time, it is recommended that the observers record the instant of the observation in sidereal time. Since this determination is in absolute time, the two astronomers will agree on the star catalogue they wish to use to regulate their clocks.

10. The observations performed at the Observatory of Milan and Padua have to be related to the place of the instrument used to the time determination. Since the trigonometric point in Milan is the spire of the cathedral and in Padova the belfry of the Saint Giustina church, so the observations have to be reduced to these points. Such a reduction is well known in Milan, but not in Padua, at least my researches about it are again doubtful. If Mr. Santini didn't get such a reduction, and we are not able to find the necessary elements at the Geographical Institute of Milan, at this aim he should make a small triangulation.

11. The last day of signalling, the signalman has to give the leave signal, i.e., 4 minutes after the tenth instantaneous fire he makes 3 bursts of powder every 2 minutes one from the other. 
12. By means of the leave signal, the observers are informed that the signalling is ended.

13. If the observers don't see the leave signal on August 25, this means that the signalman doesn't have completed his signals, but he is going to continue again. This it will happen, if a unfavourable weather prevented the signals for one or more previously fixed days.

14. It is of great importance to signalman to know if the signals have been well made, and since the method of giving counter-signals is not practicable, so the Astronomers are requested to inform daily the signalman about the outcome of the observations by usual post. The letters can be sent to Peri [village] from where they will be sent by courier to Mount Baldo.

15. The Astronomers are requested to send a copy of all their observations to the General Staff, and also to each other so that both of them can test the results and make the calculations as they like.

16. The publication of the result isn't submitted to any obstacle. At the right time Mr. Carlini will be invited to include the relation of the operation in the «Effemeridi Astronomiche» of Milan. Till that time, it is necessary to attempt not to give publicity to the thing.

\section{REFERENCES}

Archive sources

Campana, A. (1824): letter to Santini from Milan, 14 July 1824, (INAF-Astronomical Observatory of Padua, Historical Archive) (hereafter: INAF Archive).

Campana, A. (1825): letter to Santini from Milan, 29 May 1825, (INAF Archive).

Carlini, F. (1807): letter to Santini from Milan, 23 March 1807, (INAF Archive).

LoRENZONI, G. (1877): letter to Tacchini from Padua, 21 March 1877, (INAF Archive).

LorenzonI, G. (1880): ms. memorandum, Padua, January 1880, (INAF Archive).

LoREnZONI, G. (1881a): letter to Tacchini from Padua, 3 February 1881, (INAF Archive).

Lorenzoni, G. (1888): letter to Tacchini from Padua, 2 April 1888, (INAF Archive).

Lorenzoni, G. (1890): letter to Tacchini from Padua, 22 April 1890, (INAF Archive).

LoRENZONI, G. (1893): letter to Tacchini from Padua, 3 February 1893, (INAF Archive).

MARTINI, maggiore (1828): letter to Santini from Milan, 15 April 1828, (INAF Archive).

ORIANI, B. (1806): letter to Santini from Milan, 9 September 1806, (INAF Archive).

SCHIAPARELli, G.V. (1865), letter to Santini from Milan, 23 March 1865, (INAF Archive).

SCHIAPARELli, G.V. (1879): letter to Lorenzoni from Milan, 4 May 1879, (INAF Archive).

SCHIAPARELli I, G.V. (1881a): letter to Lorenzoni from Milan, 27 January 1881, (INAF Archive).

SCHIAPARELli, G.V. (1881b): letter to Lorenzoni from Milan, 18 April 1881, (INAF Archive).

TACCHINI, P. (1879): letter to Lorenzoni from Rome, $17 \mathrm{Au}-$ gust 1879, (INAF Archive).

TACCHINI, P. (1881): letter to Lorenzoni from Rome, 8 February 1881 , (INAF Archive).

\section{Bibliography}

AntoniazZi, A.M. (1915): Parole in commemorazione di Giuseppe Lorenzoni, Atti del Reale Istituto Veneto di Scienze Lettere ed Arti, pp. 1-58.

Celoria, G. and Lorenzoni, G. (1879): Resoconti delle operazioni fatte a Milano e a Padova nel 1875 in corrispondenza cogli astronomi austriaci e bavaresi per determinare le differenze di longitudine fra gli osservatori astronomici di Milano e Padova e quelli di Vienna e di Monaco [Reports about the operations performed in $\mathrm{Mi}$ lan and Padova in 1875, in collaboration with Austrian and Bavarian astronomers in order to determine the difference of longitude between the astronomical observatories of Milan and Padova, and those of Vienna and Munich], (Hoepli, Milano).

GRANATA, L. (2000): Le serie meteorologiche dell'Osservatorio astronomico di Palermo: dalle origini ai nostri giorni, in Proceedings of the «Giuseppe Toaldo e il suo tempo, nel bicentenario della morte. Scienza e Lumi tra Veneto ed Europa», Conference, Padova 10-13 novembre 1997, edited by L. PIGATTO, 'Contributi per la storia dell'Università di Padova', 33, p. 1033, (Cittadella, Bertoncello Artigrafiche), 813-840.

LoRENZONI, G. (1881b): L'Equatoriale Dembowski al Reg. Osservatorio di Padova, Atti del Reale Istituto Veneto di Scienze, Lettere ed Arti, 7, 1-2.

PigatTo, L. (1988): Santini e gli strumenti della Specola, in Giovanni Santini astronomo, «Atti e Memorie dell'Accademia Patavina di Scienze, Lettere ed Arti», (Padova), XCIX (1986-1987), 187-198.

Pigatto, L. (1996): Giovanni Santini, in Professori di materie scientifiche all'Università di Padova nell'Ottocento, edited by S. Casellato and L. Pigatto, «Contributi alla Storia dell'Università di Padova», (Profili Biografici, 1, Trieste, Edizioni Lint).

PigatTo, L. (1998): L'eclisse totale di Sole del 22 dicembre 1870. La prima spedizione scientifica del nuovo Regno d'Italia, Coelum, giugno 1998, 32-36 and luglio 1998, 32-34.

PigatTo, L. (2000): Giuseppe Toaldo: profilo biobibliografico, in Proceedings of the "Giuseppe Toaldo e il suo tempo, nel bicentenario della morte. Scienza e Lu- 
mi tra Veneto ed Europa», Conference, Padova 10-13 novembre 1997, edited by L. PIGATTO, «Contributi per la storia dell'Università di Padova», 33, p. 1033, (Cittadella, Bertoncello Artigrafiche), 5-100.

PigatTo, L. and V. ZANini (2001): Spectroscopic observations of the 1874 transit of Venus: the Italian party at Muddapur, east India, Journal of Astronomical History and Heritage, 4, 43-58.

Pigatto, L. and V. ZANini (2002): Opposition of Eros (433) of 1900-01 and the contribution of Padova Observatory to solar parallax determination, Journal of Astronomical History and Heritage, 10, 123.
TOALDO, G. (1766): De horologiis solaribus. Summa capita eorum quae traditurus est hoc anno scholastico ineunte, s.n.t., 1-2.

Tucci, P. and R. VAlota (1983): La lunga storia di Brera e la «questione» dei marziani, in Da Brera a Marte. Storia dell'osservatorio astronomico di Milano, (Nuovo Banco Ambrosiano, Milano-Italy).

Zaupa, M. (1996): Gregorio Ricci-Curbastro, in Professori di materie scientifiche all'Università di Padova nell'Ottocento, edited by S. Casellato and L. Pigatto, «Contributi alla Storia dell'Università di Padova», (Profili Biografici, 1, Trieste, Edizioni Lint). 